\title{
Expanding the spectrum of European Respiratory Society official scientific documents: short documents complement clinical practice guidelines, statements and technical standards
}

\author{
Nicolas Roche ${ }^{1}$, Thomy Tonia ${ }^{2}$, Marc Miravitlles (103 ${ }^{3}$, Valérie Vaccaro ${ }^{4}$, \\ Céline Genton ${ }^{4}$, Tobias Welte $\mathbb{1}^{5}$, Thierry Troosters ${ }^{6}$, Guy Brusselle $\mathbb{1}^{7,8}$ \\ and Chris Brightling ${ }^{9}$
}

Affiliations: ${ }^{1}$ Respiratory Medicine, Hôpital Cochin, AP-HP.Centre - Université de Paris, UMR 1016, Institut Cochin, Paris, France. ${ }^{2}$ Institute of Social and Preventive Medicine, University of Bern, Bern, Switzerland. ${ }^{3}$ Pneumology Dept, Hospital Universitari Vall d'Hebron/Vall d'Hebron Institut de Recerca (VHIR); Ciber de Enfermedades Respiratorias (CIBERES), Barcelona, Spain. "European Respiratory Society, Lausanne, Switzerland. ${ }^{5}$ University of Hannover, School of Medicine, Hannover, Germany. ${ }^{6}$ Dept of Rehabilitation Sciences, KU Leuven, Leuven, Belgium. ${ }^{7}$ Dept of Respiratory Medicine, Ghent University Hospital, Ghent, Belgium. ${ }^{8}$ Depts of Epidemiology and Respiratory Medicine, Erasmus Medical Center Rotterdam, Rotterdam, The Netherlands. ${ }^{9}$ Institute for Lung Health, NIHR Leicester Biomedical Research Centre, Dept of Respiratory Sciences, University of Leicester, Leicester, UK.

Correspondence: Nicolas Roche, Service de Pneumologie, Hôpital Cochin, 27 rue du Fbg St Jacques, 75014 Paris, France. E-mail: nicolas.rochedaphp.fr

@ERSpublications

The European Respiratory Society now issues short official scientific documents https://bit.ly/3brN9jO

Cite this article as: Roche $\mathrm{N}$, Tonia $\mathrm{T}$, Miravitlles $\mathrm{M}$, et al. Expanding the spectrum of European Respiratory Society official scientific documents: short documents complement clinical practice guidelines, statements and technical standards. Eur Respir J 2020; 55: 2001030 [https://doi.org/10.1183/ 13993003.01030-2020].

In this issue of the European Respiratory Journal (ERJ), the European Respiratory Society (ERS) releases its first "short guideline" document, dealing with inhaled corticosteroid (ICS) withdrawal in COPD [1]. This guideline belongs to a new type of "short guidance" documents developed and published by the ERS; the main goal and characteristic is the shortened timeframe between project initiation and final output, thanks to a more restricted focus. Most importantly, these documents are not short versions of original guidelines and statements: they result from an original process.

The idea behind the decision to deliver such documents was to adapt quicker to the production of new evidence, when this evidence has the potential for being "game-changing", notably when it fills an evidence gap on a clinically crucial topic. Since their launch as an ERS activity, the usual timeframe to develop ERS official scientific documents is 2 years, which remains the standard duration. Whereas this is a generally acceptable timeframe, for crucial topics as mentioned above it might imply losing a window of opportunity for providing timely guidance for clinical practice. In addition, the society receives many more requests for guideline development than it can possibly fund. This means that choices need to be made and specific clinical problems are at risk of remaining unaddressed, as they are very specific.

Published in volume 55, issue 6 of the European Respiratory Journal on 4 June 2020; republished in January 2021 with amendments to the authors' affiliation details.

Received: 5 April 2020 | Accepted after revision: 11 April 2020

Copyright OERS 2020 
Before presenting in more detail ERS short guidance documents, it may be worth recalling that the ERS produces three types of official scientific documents (figure 1): clinical practice guidelines [2-5], statements [6-10] and technical standards [11-13]. The common feature of all these documents is that they are based on systematic literature searches. When clinical practice guidelines are produced, a systematic literature review is performed [2-5]. Depending on the type of question, the results of the review are either reported narratively or using full evidence grading following the GRADE (Grading of Recommendations Assessment, Development and Evaluation) approach [14-19]. In both cases, the evidence-to-decision framework is used to transparently document how recommendations and their strength were derived from the available evidence and which factors were taken into account (including patient values, feasibility, acceptability and others). Narrative reviews are particularly indicated when questions cannot be formulated using the PICO (Population Intervention Control Outcome) format, for instance questions regarding the type and frequency of disease monitoring, treatment selection in case of specific comorbidities, etc. The best way to explain the concept of PICO questions is to use an example; the short guidance document that is accompanied by this editorial aims to address the following clinical questions: can/should ICS be withdrawn in patients with COPD receiving ICS? If the answer is yes, when and how should this be conducted? The translation in PICO format is as follows:

- Population: patients with COPD (obviously, those receiving an ICS-containing regimen);

- Intervention: ICS withdrawal;

- Control: ICS continuation;

- Outcomes (in general, these need to be defined following advice from all relevant stakeholders, mandatorily including clinicians and patients): exacerbation frequency, respiratory hospitalisations, quality of life measures, adverse effects and pneumonia. Health care resource utilisation, all-cause hospitalisation, lung function (e.g. forced expiratory volume in $1 \mathrm{~s}$ ), use of reliever medication, dyspnoea, exercise capacity and all-cause mortality.

The advantage of this format is that it forms a formalised guide for the literature search and analysis, and for formulating recommendations. Whereas systematic reviews are typically the main focus of ERS clinical practice guidelines, narrative reviews are added when necessary to guide readers on how to implement the GRADE-based recommendations in clinical practice. Altogether, the purpose of combining narrative review- and systematic review-based recommendations is to make the final guideline more complete, user-friendly and clinically applicable [14]. Statements describe the evidence and current practice [6-10]. Contrary to guidelines, although the literature search is centralised, formalised, structured and exhaustive, it is not followed by a full evidence synthesis and GRADE-ing of the evidence. As a result, they should not contain clinical practice recommendations. Finally, technical standards are meant to assess technologies

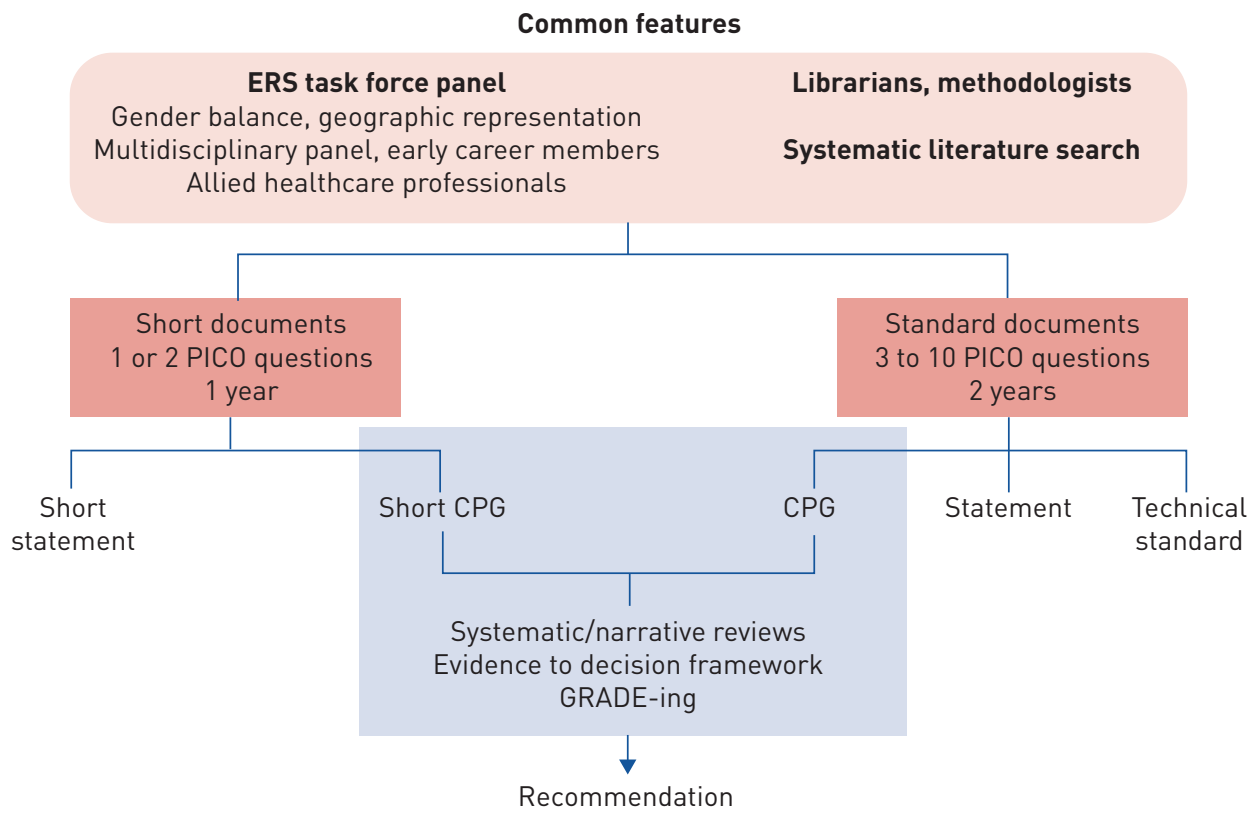

FIGURE 1 Types of European Respiratory Society (ERS) official scientific documents and their main features. CPG: clinical practice guideline. 
(e.g. diagnostic tests or technical interventions) and/or provide guidance on how these technologies should be performed and standardised [11-13]. Importantly, the focus of these documents should not be to guide decisions on whether (and when) these technologies are to be used for clinical care, since these questions are topics for clinical practice guidelines or statements. ERS requests that representatives of patients (in conjunction with the European Lung Foundation) and early career members are involved in panels, which also need to represent the diversity of ERS community from a geographical and gender perspective.

All types of documents go through a systematic validation process before final sequential endorsement by the ERS Science Council and ERS Executive Committee. All ERS official scientific documents are published in one of the ERS journals (usually the ERJ but, depending on the topic, target audience and type of document, it could also be the European Respiratory Review or ERJ Open Research) and presented at the ERS international congress in dedicated high impact symposia. Publication in a non-ERS journal may occur when the task force is jointly formed with another society. Dissemination tools also include pocket guides, key-point summaries, summaries for clinicians and patients, slide kits, webinars and promotion through social networks. Finally, official ERS scientific documents are requested to highlight areas where further research is needed and to propose studies to fill evidence gaps (including type of studies and outcomes of interest).

To fit with the "short document" process, projects should deal with topics fulfilling the following requirements:

- High clinical importance, i.e. potentially high impact on patients' outcomes;

- And/or high public health and/or economic importance, i.e. potentially high impact on healthcare systems, organisations and expenses;

- Presence of controversy or uncertainty;

- Major new evidence addressing current gaps;

- Relative urgency to provide guidance to stakeholders (clinicians, patients, decision-makers, payers, etc.).

To address such issues, the recommended process follows the general guidance for ERS official scientific documents, with some specific aspects to facilitate a quicker development:

- A markedly smaller number of questions (formulated as PICO questions for short guidelines), i.e. no more than one or two questions (versus about eight in usual guidelines);

- a more restricted panel: maximum of 10 members including the chairs, at least one member with experience in methodology, one patient representative and one early career member; taking into account gender balance and geographical representation;

- a shorter published document (2000-3000 words versus 8000).

Considering the purpose of the "short guidance" process (i.e. to accelerate the delivery of the document), applications can be submitted throughout the year and benefit from a 3-week evaluation process before a decision is made.

Although this is only an adaptation of processes already applied by the ERS and, specifically, its Guidelines Working Group (GWG) and Science Council, it was decided to perform a pilot before generalising the process, in order to test its feasibility and utility. The topic was chosen by the ERS Science Council after appropriate consultation. The result, published in this issue of the ERJ, has been obtained in 10 months. One major advantage of the document is that, as all recent ERS guidelines, it clearly differentiates situations where recommendations can be provided with various strengths that are explicitly mentioned and justified, and other circumstances where the current literature is insufficient to draw evidence-based conclusions. The availability of these recommendations is of particular importance to complement other documents, such as the Global Initiative for Chronic Obstructive Lung Disease report [20], which may also provide meaningful clinical guidance but do not rely on a similarly strict evidence-based process. It is essential for clinicians to know the extent to which propositions or recommendations for clinical practice are backed by hard data.

Altogether, this experiment has been a clear success in that the short guideline document could be developed within the requested timeframe, and proposes a top quality guideline, since it has been established following the highest available methodological standards including a systematic review, GRADE-ing of the evidence and the use of a rigorous evidence-to-decision framework. This confirms the feasibility of the approach and its compatibility with ERS functioning. Thereby, it opens the way to new projects of this type. Importantly, this pilot allowed to identify the most crucial requirement to ensure success, i.e. defining a very limited number of highly focused PICO questions with major potential for improving clinical care and patient outcomes. 
Conflict of interest: N. Roche reports grants and personal fees from Boehringer Ingelheim, Novartis and Pfizer, and personal fees from Teva, GSK, AstraZeneca, Chiesi, Sanofi, Trudell and Zambon, outside the submitted work. T. Tonia acts as an ERS methodologist. M. Miravitlles reports personal fees for lectures from AstraZeneca, Boehringer Ingelheim, Chiesi, Cipla, Menarini, Rovi, Bial, Zambon, Sandoz, CSL Behring, Grifols and Novartis, personal fees for consultancy from AstraZeneca, Boehringer Ingelheim, Chiesi, GlaxoSmithKline, Bial, Gebro Pharma, CSL Behring, Laboratorios Esteve, Ferrer, Mereo Biopharma, Verona Pharma, Kamada, TEVA, Sanofi, pH Pharma, Novartis and Grifols, grants from GlaxoSmithKline and Grifols, outside the submitted work. V. Vaccaro is an employee of the European Respiratory Society. C. Genton is an employee of the European Respiratory Society. T. Welte has nothing to disclose. T. Troosters is current president of the European Respiratory Society. G. Brusselle has nothing to disclose. C. Brightling reports grants and personal fees from GSK, AZ, Sanofi, Novartis, Chiesi, Genentech, Gossamer, Mologic and 4DPharma, outside the submitted work.

\section{References}

1 Chalmers JD, Laska IF, Franssen FME, et al. Withdrawal of inhaled corticosteroids in COPD: a European Respiratory Society guideline. Eur Respir J 2020; 55: 2000351.

2 Duijts L, van Meel ER, Moschino L, et al. European Respiratory Society guideline on long-term management of children with bronchopulmonary dysplasia. Eur Respir J 2020; 55: 1900788.

3 Holguin F, Cardet JC, Chung KF, et al. Management of severe asthma: a European Respiratory Society/American Thoracic Society guideline. Eur Respir J 2020; 55: 1900588.

4 Morice AH, Millqvist E, Bieksiene K, et al. ERS guidelines on the diagnosis and treatment of chronic cough in adults and children. Eur Respir J 2020; 55: 1901136.

5 Ergan B, Oczkowski S, Rochwerg B, et al. European Respiratory Society guidelines on long-term home non-invasive ventilation for management of COPD. Eur Respir J 2019; 54: 1901003.

6 Laveneziana P, Albuquerque A, Aliverti A, et al. ERS statement on respiratory muscle testing at rest and during exercise. Eur Respir J 2019; 53: 1801214

7 Wallis C, Alexopoulou E, Antón-Pacheco JL, et al. ERS statement on tracheomalacia and bronchomalacia in children. Eur Respir J 2019; 54: 1900382.

8 Grünig E, Eichstaedt C, Barberà J-A, et al. ERS statement on exercise training and rehabilitation in patients with severe chronic pulmonary hypertension. Eur Respir J 2019; 53: 1800332.

9 Chiumello D, Sferrazza Papa GF, Artigas A, et al. ERS statement on chest imaging in acute respiratory failure. Eur Respir J 2019; 54: 1900435.

10 Bonniaud P, Fabre A, Frossard N, et al. Optimising experimental research in respiratory diseases: an ERS statement. Eur Respir J 2018; 51: 1702133

11 Hallstrand TS, Leuppi JD, Joos G, et al. ERS technical standard on bronchial challenge testing: pathophysiology and methodology of indirect airway challenge testing. Eur Respir J 2018; 52: 1801033.

12 Zavorsky GS, Hsia CCW, Hughes JMB, et al. Standardisation and application of the single-breath determination of nitric oxide uptake in the lung. Eur Respir J 2017; 49: 1600962.

13 Graham BL, Brusasco V, Burgos F, et al. 2017 ERS/ATS standards for single-breath carbon monoxide uptake in the lung. Eur Respir J 2017; 49: 1600016.

14 Miravitlles M, Tonia T, Rigau D, et al. New era for European Respiratory Society clinical practice guidelines: joining efficiency and high methodological standards. Eur Respir J 2018; 51: 1800221.

15 Alonso-Coello P, Schünemann HJ, Moberg J, et al. GRADE Evidence to Decision (EtD) frameworks: a systematic and transparent approach to making well informed healthcare choices. 1: Introduction. BMJ 2016; 353 : i2016.

16 Alonso-Coello P, Oxman AD, Moberg J, et al. GRADE Evidence to Decision (EtD) frameworks: a systematic and transparent approach to making well informed healthcare choices. 2: Clinical practice guidelines. BMJ 2016; 353: i2089.

17 Alper BS, Oettgen P, Kunnamo I, et al. Defining certainty of net benefit: a GRADE concept paper. BMJ Open 2019; 9: e027445.

18 Guyatt GH, Oxman AD, Vist GE, et al. GRADE: an emerging consensus on rating quality of evidence and strength of recommendations. BMJ 2008; 336: 924-926.

19 Jaeschke R, Guyatt GH, Dellinger P, et al. Use of GRADE grid to reach decisions on clinical practice guidelines when consensus is elusive. BMJ 2008; 337: a744.

20 Singh D, Agusti A, Anzueto A, et al. Global Strategy for the Diagnosis, Management, and Prevention of Chronic Obstructive Lung Disease: the GOLD science committee report 2019. Eur Respir J 2019; 53: 1900164. 